\title{
Efek Refugia Tanaman Jagung (Zea mays) dan Tanaman Kacang Panjang (Vigna cylindrica) pada Pola Kunjungan Serangga di Sawah Padi (Oryza sativa) Dusun Balong, Karanglo, Malang
}

\author{
Yuris Setyadin ${ }^{1)}$, Sakinah Hilya Abida), Haidar Azzamuddin ${ }^{1)}$, S. Fatiyatur Rahmah ${ }^{1)}$, Amin Setyo Leksono ${ }^{\left.2^{*}\right)}$ \\ ${ }^{1)}$ Madrasah Aliyah Negeri 3 Malang \\ ${ }^{2)}$ Jurusan Biologi, Fakultas Matematika dan Ilmu Pengetahuan Alam, Universitas Brawijaya,Malang \\ Alamat korespondensi": amin28@ub.ac.id
}

\begin{abstract}
ABSTRAK
Hama padi merupakan masalah yang menuntut untuk ditangani secara efektif, mudah, dan murah. Penggunaan pestisida sebagai solusi terbukti membawa dampak negatif sehingga perlu dikembangkan inovasi pengendalian hama, salah satunya adalah refugia. Refugia jagung dan kacang panjang menjadi salah satu solusi terbaik dalam berbagai aspek. Penelitian ini bertujuan untuk mengetahui kelimpahan, struktur komunitas, dan diversitas serangga di lahan persawahan padi di Desa Tunjungtirto, Kecamatan Singosari, Kabupaten Malang. Metode yang digunakan adalah visual kontrol terhadap serangga pengunjung blog refugia. Pengambilan data dilakukan sebanyak tiga kali sehari pada fase vegetatif dan generatif tanaman refugia selama 15 menit. Hasil penelitian menunjukkan bahwa tanaman refugia di sawah padi dapat menyeimbangkan populasi serangga herbivora, predator, dan polinator. Dibuktikan dengan persentase kelimpahan relatif herbivora yang lebih rendah. Struktur komunitas di sawah dengan refugia lebih seimbang, INP menunjukkan bahwa family Acrididae (56,66\%) memiliki peran yang penting dalam ekosistem sawah, dan Indeks Diversitas Shanon-Winner menunjukkan diversitas yang lebih beragam dibanding sawah tanpa refugia.
\end{abstract}

Kata kunci : Keanekaragaman, Refugia, Sawah, Serangga, Struktur komunitas

\section{ABSTRACT}

Insect pests of rice is a problem that demands to be handled effectively, easily, and inexpensively. The use of pesticides as a solution proven to have negative impacts thus it is necessary to develop the innovation to manage pests, one of which is refugia. Refugia of corn and beans to be one of the best solutions in various aspects. This study aims to determine the abundance, community structure, diversity of insect visitors of refugia in the rice paddy fields in Village Tunjungtirto, Singosari, Malang regency. The method used is the visual encounter surveys against insects. Data retrieval was performed three times a day on the phase of vegetative and generative plant refugia for $\mathbf{1 5}$ minutes. The results showed that the plant refugia in paddy fields can balance the population of insect herbivores, predators, and pollinators. This was evidenced by the percentage of relative abundance of herbivorous was lower in paddy field with refugia. Community structure in the rice fields refugia was more balanced, IVI (important value index) showed that the family Acrididae (56,66\%) have an important role in the ecosystem of rice fields. The diversity of insect in that with refugia was greather than that without refugia.

Keywords: Diversity,Refugia, Paddy field, Insect, Community structure

\section{PENDAHULUAN}

Padi merupakan bahan pangan pokok dan kebutuhan dasar masyarakat Indonesia,sehingga padi menjadi tanaman pangan yang sangat penting dan dibutuhkan. Tingginya jumlah pertumbuhan penduduk Indonesia menjadi salah satu kendala dalam pemenuhan kebutuhan pangan. Selain itu, hama serangga terutama wereng coklat, Nilaparvata lugens, menjadi hambatan yang sangat terasa pada persawahan padi Indonesia $[1,2]$. Serangan hama wereng coklat pada 2005 terpusat di pulau Jawa dengan luas mencapai 56.832 ha [3]. Sampai saat ini upaya pengendalian hama dilakukan dengan menggunakan insektisida khususnya insektisida kimiawi yang memberikan dampak negatif terhadap organisme non target, manusia dan lingkungan [4].

Banyaknya dampak negatif yang ditimbulkan dari pemberian pestisida mengharuskan penggunaannya untuk dikurangi. Salah satu cara yang tengah dikembangkan 
adalah rekayasa ekosistem dengan refugia. Rekayasa yang dilakukan adalah dengan menyediakan habitat bagi predator hama. Penanaman refugia bertujuan untuk menurunkan penggunaan pestisida, meningkatkan produksi beras dan menjaga keseimbangan ekosistem [5].

Refugia merupakan suatu mikro habitat yang menyediakan tempat berlindung sementara bagi musuh alami hama, seperti predator dan parasitoid,serta memberi keuntungan terhadap interaksi biotik ekosistem, seperti polinator [6]. Area khusus ini juga mampu menyediakan inang alternatif dan makanan tambahan bagi imago parasitoid saat kondisi lingkungan tidak sesuai $[7,8,9,10]$.

Berdasarkan hal tersebut,studi ini akan mengkaji nilai kelimpahan relatif (KR), struktur komunitas, diversitas serangga, efek refugia terhadap pola kunjungan serangga, pengaruh faktor abiotik, serta status fungsional serangga di lahan persawahan padi. Tanaman refugia yang diteliti yaitu jagung (Zea mays) dan kacang panjang (Vigna cylindrica) yang ditanam di pematang sawah padi (Oryza sativa).

\section{METODE PENELITIAN}

Penelitian ini dilaksanakan pada Juni sampai Juli 2016 di Lahan Pertanian Padi di Desa Tunjungtirto, Kecamatan Singosari, Kabupaten Malang. Pengamatan Arthropoda dilakukan dengan metode visual kontrol (visual encounter survey) sebanyak 3 kali pada fase vegetatif dan 3 kali pada fase generatif sehari di setiap kombinasi refugia selama 15 menit setiap periode (09.00-10.00, 12.00-13.00, dan 15.0016.00). Serangga yang tidak dapat diidentifikasi di tempat dicuplik dan diidentifikasi di Laboratorium Biodiverstas Hewan Jurusan Biologi, Fakultas Matematika dan Ilmu Pengetahuan Alam, Universitas Brawijaya Malang.

Analisis struktur komunitas serangga dan keanekaragaman pada setiap blok didapatkan dari nilai indeks nilai penting (INP) dan diversitas (IndeksShannon-Wienner) (ISW), serta kesamaan komunitas (Indeks Bray Curtis) (IBC). Analisis dilakukan dengan menggunakan program PAST. Analisis efek blok refugia dengan membandingkan rata-rata individu pada setiap blok serta selisih kelimpahan serangga antara blok refugia dengan kontrol. Pengaruh faktor abiotik dan peran ekologis serangga dijelaskan secara deskriptif.

\section{HASIL DAN PEMBAHASAN}

\section{Kelimpahan, Indeks Nilai Penting, Diversitas dan Tingkat Kesamaan Serangga Pengunjung Blok Refugia.}

Jumlah total individu yang diamati adalah 260 individu terdiri dari 7 ordo dengan 25 famili. Pada lahan sawah masa vegetatif famili yang memiliki kelimpahan relatif terbesar adalah Acrididae, Menochilus, dan Formicidae (Gambar 1). Tingginya kelimpahan Acrididae yang berperan sebagai herbivora di lahan sawah masa vegetative dikarenakan serangga Acrididae mencari dan mendapatkan inang yang sesuai pada saat padi pada masa vegetative yaitu rumput dan tumbuhan semak lain.

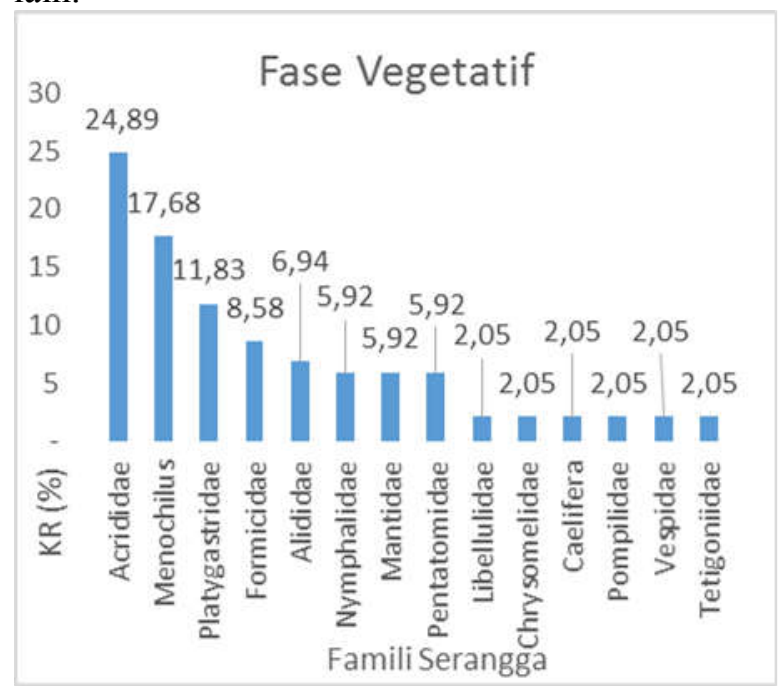

Gambar 1. Kelimpahan Relatif Arthropoda Pengunjung Blok Refugia pada Padi Fase Vegetatif.

Adapun kelimpahan serangga Acrididae tertinggi didapatkan di lahan sawah tanpa tanaman refugia. Hal ini disebabkankan kurangnya populasi serangga predator sehingga jumlah Acrididae meningkat. Populasi serangga predator yang kurang tidak dapat menanggulangi dan menyeimbangkan jumlah serangga herbivora yang dapat merusak tanaman padi dikarenakan tidak adanya tempat berlindung dan sembunyi untuk serangga predator.

Pada masa padi generatif, famili dengan kelimpahan relatif terbesar adalah Acrididae, Menochilus, Sarcophagidae, dan Vespidae (Gambar 2). Serangga Acrididae berperan sebagai herbivor dan paling banyak ditemukan pada sawah tanpa tanaman refugia. Sedangkan serangga Minochilus dan Sarcophagidae 
berperan sebagai predator dan paling banyak ditemukan di sawah dengan tanaman refugia. Adapun serangga Vespidae merupakan predator dan paling banyak ditemukan di sawah dengan tanaman refugia. Adanya perbedaan jenis famili antara musim sebelum berbunga dan musim setelah berbunga ini dipengaruhi karena adanya perbedaan vegetasi sawah. Kelimpahan dan keanekaragaman serangga mempunyai nilai yang tinggi pada saat musim setelah berbunga dikarenakan banyaknya keanekaragaman jenis makanan yang tersedia yaitu berupa bunga padi dan vegetasi liar lainnya.

Pertumbuhan populasi organisme dipengaruhi oleh ketersediaan dan variabilitas sumber daya yang ada pada masing-masing habitatnya [11]. Kelimpahan serangga pada suatu habitat ditentukan oleh keanekaragaman dan kelimpahan pakan maupun sumberdaya lain yang tersedia pada habitat tersebut[12].

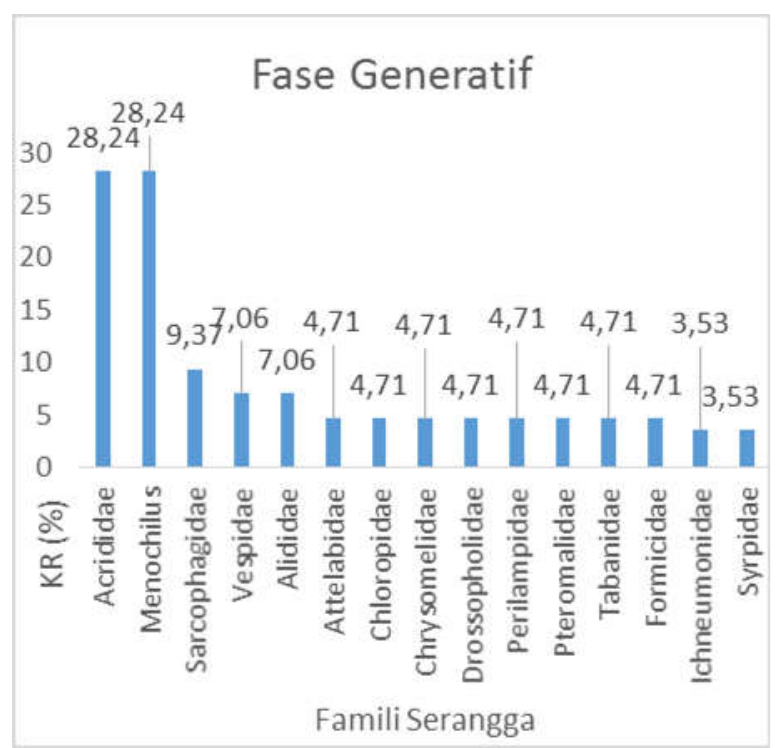

Gambar 2. Kelimpahan Relatif Arthropoda Pengunjung Blok Refugia pada Padi Fase Generatif.

Indeks Nilai Penting (INP) menunjukkan besarnya pengaruh suatu famili terhadap struktur komunitas suatu ekosistem. Famili yang dominan yaitu famili yang mempunyai INP $>10 \%$ [8]. Pada lahan sawah vegetatif nilai INP tertinggi adalah famili Acrididae (56,66\%), kemudian Formicidae $(43,34 \%)$, Aleydidae (19,27\%), Minochilus (16.25\%), dan

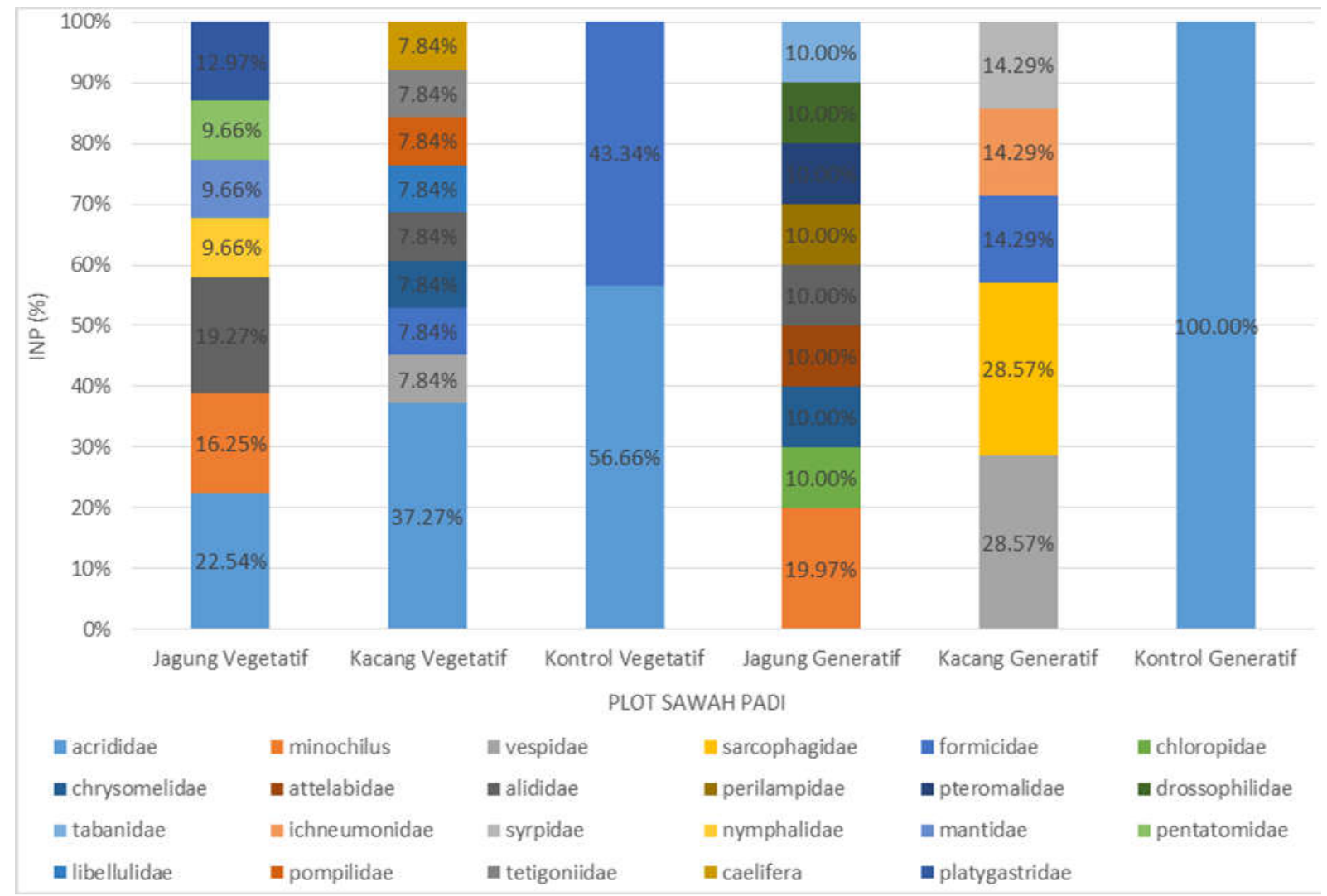

Gambar 3. Indeks Nilai Penting pada masing-masing plot sawah 
Platygastridae (12,97\%) (Gambar 3).

Adapun di lahan sawah generatif famili arthropoda yang memiliki INP tertinggi adalah Acrididae (100\%), dan seluruh famili yang ada memiliki nilai INP yang di atas $10 \%$ sehingga semua famili mendominasi lahan tersebut, yakni Minochilus (19,97\%), Vespidae $(28,57 \%)$ Sarcophagidae $(28,57 \%)$, nilai $10,00 \%$ untuk famili Chloropidae, Chrysomelidae, Attelabidae, Alididae, Perilampidae, Pteromalidae, Drossopholidae, Tabanidae, serta nilai $14,29 \%$ untuk famili Formicidae dan Syrpidae. Adanya

dominansi pada lahan sawah tersebut menunjukkan bahwa struktur komposisi serangga Arthropoda tidak merata, dikarenakan dominansi menunjukkan adanya prioritas jumlah dibandingkan dengan peran famili tersebut.

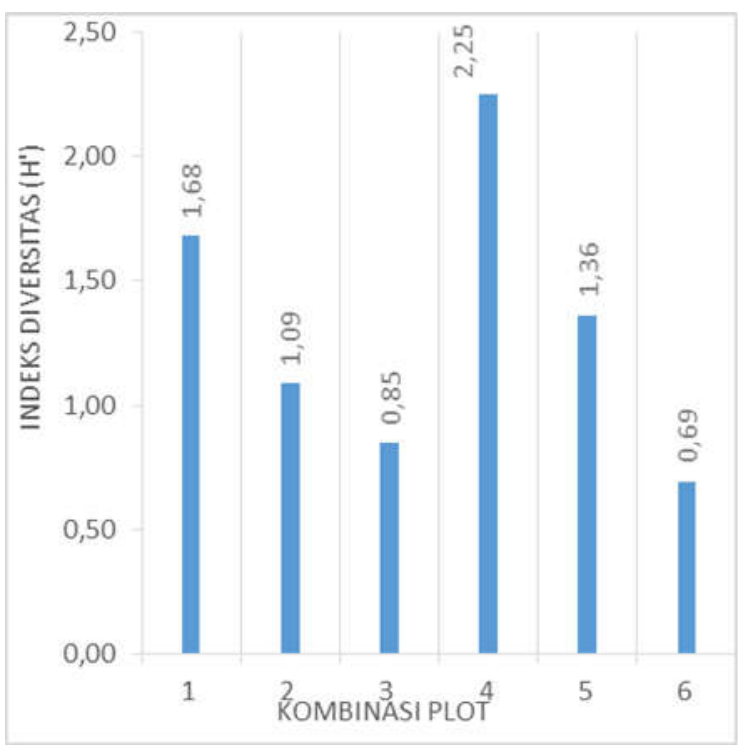

Gambar 4. Diversitas serangga pengunjung blok refugia (plot 1: jagung vegetatif; plot 2: kacang vegetatif; plot 3 ; control vegetatif; plot 4 ; jagung generatif; plot 5 ; kacang generatif; plot 6 ; control generatif)

Nilai indeks diversitas pada plot 4 (refugia jagung fase geneartif) menunjukkan nilai tertinggi $(2,25)$ dibandingkan dengan plot lainnya, sedangkan yang terendah adalah plot 6 $(0,69)$. Secara keseluruhan ini menunjukan tingkat diversitas sedang sampai tinggi. Hal ini menunjukkan adanya kestabilan lingkungan yang tinggi, sehingga interaksi antar spesies yang terjadi pada plot 4 juga tinggi. Keanekaragaman yang tinggi merupakan indikator dari kestabilan suatu lingkingan hidup. Jika dibandingkan dengan plot 3 dan 6 (kontrol tanpa refugia), plot dengan refugia memiliki nilai Indeks Diversitas yang cenderung lebih tinggi. Sehingga dengan penanaman refugia akan menambahkan kestabilan ekosistem lingkungan.

\section{KESIMPULAN DAN SARAN}

Tanaman refugia dapat menjadi agen hayati pengendali hama terpadu serangga herbivora pada sawah padi. Diversitas serangga pada sawah padi dengan blok refugia cenderung lebih seimbang. Faktor abiotik seperti intensitas cahaya,suhu,dan kelembapan mendukung tumbuh kembang tanaman serta serangga. Di sawah padi dengan blok refugia status fungsional dari serangga tidak didominasi satu status fungsional saja.

Dilakukan penelitian lebih lanjut dengan ragam variable bebas yang lebih banyak agar data mengenai efek blok refugia lebih beragam dan valid. Dan juga dilakukan uji mengenai ada tidaknya efek ekologis,dan efek evolusi pada lahan pertanian secara lebih lanjut lanjut.

\section{UCAPAN TERIMAKASIH}

Penulis mengucapkan terimaksih kepada Guru dan Pengelola MAN 3 Malang. Tidak lupa juga penulis ucapkan terimakasih kepada Dra. Catur Retnaningdyah, M.Si. atas segala bantuan selama penelitian di lapangan maupun di Laboratorium Ekologi dan Diversitas Hewan Jurusan Biologi. Universitas Brawijaya.

\section{DAFTAR PUSTAKA}

[1] Effendi, B. S.,1986. Dinamika populasi wereng coklat Nilaparvata lugens Stal. Wereng Coklat, Edisi Khusus(1).

[2] Effendi, B. S., 1999. Strategi pengendalian wereng coklat. Sukamandi, Balai Penelitian Tanaman Padi.

[3] Effendi, B. S., 2009. Strategi Pengendalian Hama Terpadu Tanaman Padi Dalam Perspektif Praktek Pertanian yang Baik (Good Agricultural Practice). Pengembangan Inovasi Pertanian,2(1), pp. 65-78.

[4] Yuantari, M. G. C.,Widianarko, B. \& Sunoko, H. R., 2015. Analisa Resiko Pajanan Pestisida Terhadap Kesehatan Petani. Jurnal Kesehatan Masyarakat, 10(2),pp. 239-245.

[5] Horgan, F. G. et al., 2016. Applying ecological engineering for sustainable and resilient rice production systems. 
Procedia Food Science, Volume 6,pp. 715.

[6] Keppel, G. et al.,2012. Refugia: Identifying and Understanding Safe Havens for Biodiversity Under Climate Change. Global Ecology and Biogeography, Volume 21,pp. 393-404.

[7] Dadi,2010. Potensi Agroforestri pendukung Eksistensi Arthropoda Predator Wereng Padi Di Ekosistem Sawah. Malang,Fakultas Pertanian UB.

[8] Nursaidah, I., \& Leksono, A. S. 2013. Pengaruh Resiko Pembelian,Harga atas Kualitas Produk,Kontrol Perilaku,Norma Subjektif,dan Integritas Terhadap Sikap dan Minat Pembelian CD Musik Bajakan di Kota Jember. JEAM, 12(1), pp. 29-63.

[9] Sari, R. P. \& Yanuwiadi, B., 2014. Efek Refugia Pada Populasi Herbivora di Sawah Padi Merah Organi Desa Sangguruh, Kepanjen, Malang. Jurnal Biotropika, 2(1), pp. 14-19.

[10] Wardani, F. S., Leksono, A. S. \& Yanuwiadi, B., 2013. Efek Blok Refugia Ageratum conyzoides, Ageratum houstonianum, Commelina diffusa Terhadap Pola Kunjungan Arthropoda di Perkebunan Apel Desa Poncokusumo,Malang. Jurnal Biotropika, 1(4), pp. 134-138.

[11] Krebs, C. J., 2001. Ecology: The Experimental Analysis of Distribution and Abundance. Edisi 5. California: Benjamin Cummings. 